\title{
Why is information governance important for electronic healthcare systems? A Canadian experience
}

\author{
Linying Dong ${ }^{1 *}$, Karim Keshavjee ${ }^{2}$ \\ Ryerson University, Toronto, Ontario
}

\author{
Key Words \\ Information governance \\ Electronic healthcare \\ Canadian experience \\ Governance model
}

Received: 25 May 2016

Accepted: 10 August 2016

Published: 27 October 2016

\begin{abstract}
The objective of this paper is to propose an information governance model for the Ontario health care system. This study first defines information governance, describes information governance maturity level, and introduces the data governance model to achieve the goal. Then it explains the information governance model for the Ontario healthcare system, applies the model to a case study, and demonstrates how the model can be applied to identify key problems and suggest a future action plan. Using the Canadian healthcare system as the backdrop, the study, drawing on the eight principles of information governance outlined by the Association of Records Managers and Administrators (ARMA) and the Data Governance Model, proposes an information governance framework detailing how information should be governed from four dimensions: people, process, policy, and technology. The model is then applied to analyze a case study on the 18-month well-baby visit program. After analyzing the findings from the case, the paper concludes with the implications for healthcare practitioners. The study contributes to the academic study on information governance by offering a well-defined model to practitioners by suggesting effective approaches to information governance.
\end{abstract}

(C)2016 The Author(s). Published by TAF Publishing.

\section{INTRODUCTION}

Since Electronic Medical Records (EMR) adoption program started in 2005, Canadian governments at all levels have been pushing for the EMR adoption among physicians with the aim to enhance the quality of care while reducing operating costs. There are 29,368 physicians in Ontario, a little over half $(14,695)$ of which are family physicians who are also known as primary care providers (Vuchnich, 2015). The recent progress report, published in 2015 by eHealth Ontario, has indicated that 7 out of 10 primary care physicians are using EMR software in their practice and that 2 out of 3 Ontarians are covered by EMR software (eHealth Ontario, 2016). In addition, over $80 \%$ of healthcare data are digitalized (Ontario Medical Association, 2014). As the result of the prevalent EMR adoption, physicians start to enjoy faster report transfer (reduced from 12 days to 30 minutes) and easy access to lab results (over 3,000 types of lab results can now be accessed through physician's EMR software). Despite the remarkable accomplishments achieved, to what extent the EMR adoption increases the quality of care remains unclear. As the matter of fact, it has been argued that healthcare organizations may be facing "faster incorrect information" (Greene 2014), as different healthcare organizations have implemented their own technology applications (Reeves and Rita, 2013), which use inconsistent metrics and generate data in different formats (Greene, 2014), creating faulty data that could lead to medical errors (Hripscak and David, 2012).

\footnotetext{
${ }^{*}$ Corresponding author: Linying Dong

†Email: ldong@ryerson.ca
} 
Health data are the lifeblood of a healthcare system. They serve as the foundation to develop best practices and make critical clinical decisions (Bowen and Alisha, 2014). It is argued that quality data support high quality care, accurate research, positive patient outcomes, cost effective risk assessment, and strategic decision making" (Wood 2014). As the result, the proliferation of electronic health data requires a well-defined systematic data governance framework in place to ensure data quality. Without quality data, "organizations are spending more to be less efficient and less effective" (Wood, 2014), and the objective of improving quality care would be elusive.

Data/information governance has just gained attention in the healthcare sector. Canada Health Infoway has emphasized the need to develop a data/information governance framework to govern information flow in the interoperable (Canada Health Infoway, 2007). Ontario Medical Association, while agreeing on the importance of having a data/information governance model, indicates that there is no clear framework governing what information should and should not flow from a physician's EMR to the system-wide EHR.

With the backdrop, the objective of this paper is to propose an information governance model for the Ontario health care system. To achieve the goal, we first define information governance, describe information governance maturity level, and introduce the data governance model. Then we explain the information governance model for the Ontario healthcare system, apply the model to a case study, and demonstrate how the model can be applied to identify key problems and suggest the future action plan.

\section{LITERATURE REVIEW}

\section{Information Governance}

Information governance is denoted as "the exercise of decision making and authority on matters related to data and information" (Ontario Medical Association 2014). Information governance manages the entire life cycle of the information flow, including how it is created, stored, used, and archived (Greene, 2014), and defines who should have access to certain information at what time and using what methods (Scardilli, 2014). It is argued that information governance is "a strategic effort that requires executive ownership, leadership support, and participation of everyone within the organization" (Isaacs, 2016).

Information governance differs from data governance in that data governance focuses on processes and control related to information at the data level, and the goal of data governance is to ensure that data are accurate and secure (Smallwood, 2014). Data governance falls under the domain of IT governance. How is information governance related to IT governance? IT governance specifies the decision rights and accountability framework to encourage desirable behavior in IT usage (Weill and Jeanne, 2004), and lies in the hands of CIO. The objective of IT governance is to ensure value-delivery of IT investments through "effective and efficient use of IT" (Gerrard, 2010). In contrast, information governance is about governance of information, and the goal of information governance is to ensure reliable, accurate, secure, and compliant information access to support/enhance existing functions and/or to enable new functions of an organization to help achieve its business goals. Managing information governance lies in the Information Governance office.

Table 1 summarizes the differences of the three governance concepts. Despite the differences, information governance and IT governance are inseparable. An effective information governance program relies on the support of information technologies to manage information governance policies and processes, engage stakeholders, and ensure data quality. On the other hand, IT governance is dependent on information governance to 
identify information that needs to be managed, define criteria for data quality, determine decision rights, and identify stakeholders involved. The information is necessary for the IT department to identify a suitable technology supporting information governance. Ultimately, the technology investment should support the mission and vision of information governance.

TABLE 1. Comparison of information governance, data governance, and IT governance

\begin{tabular}{|c|c|c|c|}
\hline & Information governance & Data governance & IT governance \\
\hline Focus area(s) & $\begin{array}{l}\text { Define policies, involve people, } \\
\text { and manage processes related to } \\
\text { data and information }\end{array}$ & $\begin{array}{l}\text { Data definitions, rules, and secu- } \\
\text { rity }\end{array}$ & $\begin{array}{l}\text { Decision rights and accountabil- } \\
\text { ity related to IT investments }\end{array}$ \\
\hline Objective & $\begin{array}{l}\text { To ensure reliable, accurate, se- } \\
\text { cure, and compliant information } \\
\text { access }\end{array}$ & $\begin{array}{l}\text { To ensure data quality (e.g. in- } \\
\text { tegrity, completeness) and secu- } \\
\text { rity }\end{array}$ & $\begin{array}{l}\text { To ensure business value from IT } \\
\text { investment }\end{array}$ \\
\hline
\end{tabular}

\section{Information Governance Maturity}

The Association of Records Managers and Administrators (ARMA) has developed eight principles guiding information governance including accountability (i.e. a senior executive is in charge of the information governance program, and information and records management is delegated to appropriate individuals), transparency (i.e. processes and activities including information governance program are documented and openly shared to all involved personnel and interested parties), integrity (i.e. information generated is authentic and reliable), protection (i.e. information generated is securely protected to ensure privacy and confidentiality), compliance (i.e. an information governance program should be compliant with relevant laws and organizational policies), retention (i.e. records and information are maintained for a given time based on the legal and regulatory requirements), availability (i.e. timely, efficient, and accurate information retrieval), and disposition (i.e. records and information are securely and appropriately disposed once they are no long required).

Based on the eight guiding principles for information governance, the Association of Records Managers and Administrators (ARMA) proposes five levels of maturity of information governance. Level one (Sub-standard) describes an organizational environment where there is no program managing information governance and there lacks recognition of the importance of information governance. In addition, there is no designated person in charge of information governance, consequently there is unsystematic effort in managing information across an entire organization. The five levels are summarized in Table 2.

Level two (In Development) captures an organizational environment where the importance of information governance is somewhat recognized and the organization is benefitting from the information governance program. A managerial position is created to manage information; however, the focus of information governance is limited to some format of information, and there lacks systematic effort in managing information assets.

An organization at level three (Essential) has a clearly defined information governance program. The importance of information governance is recognized by senior managers, and as a result, there is a company-wide effort in information governance, and the manager who is in charge of information governance is actively engaged in strategic initiatives of the organization. 
At level 4 (Proactive), an organization has established well-defined procedures and policies on various aspects of information governance and information governance practices have become an integral part of routine business operations. Information governance is overseen by a senior manager, and plays a critical role in enhancing performance and building competitiveness.

TABLE 2. Summary of information governance maturity levels

\begin{tabular}{|c|c|c|c|c|c|}
\hline $\begin{array}{l}\text { Level } \\
\text { Principle }\end{array}$ & $\begin{array}{l}\text { Level one } \\
\text { Substandard }\end{array}$ & $\begin{array}{l}\text { Level Two } \\
\text { In development }\end{array}$ & $\begin{array}{l}\text { Level Three } \\
\text { Essential }\end{array}$ & $\begin{array}{l}\text { Level Four } \\
\text { Proactive }\end{array}$ & $\begin{array}{l}\text { Level Five } \\
\text { Transformational }\end{array}$ \\
\hline Accountability & $\begin{array}{l}\text { No senior executive } \\
\text { responsible; no } \\
\text { records manager } \\
\text { role }\end{array}$ & $\begin{array}{l}\text { No senior executive } \\
\text { in charge; records } \\
\text { manager role recog- } \\
\text { nized }\end{array}$ & $\begin{array}{l}\text { Records manager } \\
\text { actively engaged } \\
\text { in strategic info. } \\
\text { mgmt. }\end{array}$ & $\begin{array}{l}\text { Records manager is } \\
\text { a senior officer }\end{array}$ & $\begin{array}{l}\text { Great emphasis } \\
\text { placed on the im- } \\
\text { portance of info. } \\
\text { governance }\end{array}$ \\
\hline Transparency & $\begin{array}{l}\text { No emphasis on } \\
\text { transparency }\end{array}$ & $\begin{array}{l}\text { A limited amount of } \\
\text { transparency }\end{array}$ & $\begin{array}{l}\text { Written policy on } \\
\text { transparency }\end{array}$ & $\begin{array}{ll}\text { Transparency, an } \\
\text { essential part of } \\
\text { practice }\end{array}$ & $\begin{array}{l}\text { Goals for trans- } \\
\text { parency are rou- } \\
\text { tinely reviewed and } \\
\text { revised }\end{array}$ \\
\hline Integrity & $\begin{array}{l}\text { No systematic } \\
\text { audits or defined } \\
\text { processes }\end{array}$ & $\begin{array}{l}\text { Some records } \\
\text { stored can demon- } \\
\text { strate authenticity }\end{array}$ & $\begin{array}{l}\text { Formal process en- } \\
\text { suring integrity }\end{array}$ & $\begin{array}{l}\text { Integrity, an integral } \\
\text { part of info. mgmt. }\end{array}$ & $\begin{array}{l}\text { Goals for integrity } \\
\text { are routinely re- } \\
\text { viewed and revised }\end{array}$ \\
\hline Protection & $\begin{array}{l}\text { No consideration } \\
\text { given to informa- } \\
\text { tion protection }\end{array}$ & $\begin{array}{l}\text { Some protection is } \\
\text { applied }\end{array}$ & $\begin{array}{l}\text { Formal policy on } \\
\text { info. protection }\end{array}$ & $\begin{array}{l}\text { Systems in place to } \\
\text { protect info. }\end{array}$ & $\begin{array}{l}\text { Goals for protection } \\
\text { are routinely re- } \\
\text { viewed and revised }\end{array}$ \\
\hline Compliance & Poor compliance & Limited compliance & $\begin{array}{l}\text { Compliant to key } \\
\text { laws and regula- } \\
\text { tions }\end{array}$ & $\begin{array}{l}\text { Effective } \\
\text { process }\end{array}$ & $\begin{array}{lr}\text { Goals for } & \text { compli- } \\
\text { ance are } & \text { routinely } \\
\text { reviewed } & \text { and } \\
\text { revised } & \\
\end{array}$ \\
\hline Availability & $\begin{array}{l}\text { Info. not readily } \\
\text { available }\end{array}$ & $\begin{array}{l}\text { Limited retrieval } \\
\text { info. mechanism }\end{array}$ & $\begin{array}{l}\text { Established stan- } \\
\text { dards for info. } \\
\text { retrieval }\end{array}$ & $\begin{array}{l}\text { Systems and control } \\
\text { in place to guard } \\
\text { info. access }\end{array}$ & $\begin{array}{l}\text { Goals for availabil- } \\
\text { ity are routinely re- } \\
\text { viewed and revised }\end{array}$ \\
\hline Retention & $\begin{array}{l}\text { No info. retention } \\
\text { policies }\end{array}$ & $\begin{array}{l}\text { Limited policies on } \\
\text { info. retention }\end{array}$ & $\begin{array}{l}\text { Established policy } \\
\text { for info. retention }\end{array}$ & $\begin{array}{l}\text { Info. retention, a } \\
\text { major organiza- } \\
\text { tional objective }\end{array}$ & $\begin{array}{l}\text { Goals for retention } \\
\text { are routinely re- } \\
\text { viewed and revised }\end{array}$ \\
\hline Disposition & $\begin{array}{l}\text { No policies on info. } \\
\text { disposition }\end{array}$ & $\begin{array}{l}\text { Limited policies on } \\
\text { retention }\end{array}$ & $\begin{array}{l}\text { Established policies } \\
\text { for info. disposition }\end{array}$ & $\begin{array}{l}\text { Procedures consis- } \\
\text { tently applied }\end{array}$ & $\begin{array}{lr}\text { Goals for } & \text { disposi- } \\
\text { tion are } & \text { routinely } \\
\text { reviewed } & \text { and } \\
\text { revised } & \\
\end{array}$ \\
\hline
\end{tabular}

At level 5 (Transformational), an organization has built a continuous improvement mechanism in its information governance program, and the initial goals of information governance are routinely reviewed and revised to ensure that the organization is fully compliant and continue to enjoy the benefits of information governance on a plenary basis.

Data Governance Model

The Data Governance Institute (DGI) proposes ten universal components of a data governance model (see Table 3) which are grouped into three categories: rules and rules of engagement, people and organizational bodies, and processes. Rules and rules of engagement category describes rules (e.g. policies, standards) that need to be made and how people work together to develop and enforce the rules. Components under the category include mission and vision of a data governance program, metrics and success measures, data rules and definitions, decision rights, accountabilities, and controls (e.g. access).

The people and organizational bodies category describes the stakeholders who make and enforce the rules defined above, and includes components such as data stakeholders, a data governance office, and data stewards. The processes category denotes proactive, ongoing processes that people follow to govern data. 
TABLE 3. Data governance model

\begin{tabular}{|c|c|c|}
\hline Category of components & Description & Detailed list \\
\hline Rules and Rules of Engagement & $\begin{array}{l}\text { Describes rules (e.g. policies, re- } \\
\text { quirements, standards) and how } \\
\text { different people work together } \\
\text { to make these rules and enforce } \\
\text { them }\end{array}$ & $\begin{array}{l}\text { 1. Mission and Vision 2. Goals, } \\
\text { Governance Metrics and Success } \\
\text { Measures, and Funding Strategies } \\
\text { 3. Data Rules and Definitions } 4 . \\
\text { Decision Rights 5. Accountabili- } \\
\text { ties 6. Controls }\end{array}$ \\
\hline People and Organizational Bodies & $\begin{array}{l}\text { Stakeholders who make and en- } \\
\text { force the rules }\end{array}$ & $\begin{array}{l}\text { 7. Data Stakeholders 8. A Data } \\
\text { Governance Office 9. Data Stew- } \\
\text { ards }\end{array}$ \\
\hline Processes & $\begin{array}{l}\text { Describe the processes that peo- } \\
\text { ple follow to govern data }\end{array}$ & $\begin{array}{l}\text { 10. Proactive, Reactive, and Ongo- } \\
\text { ing Data Governance Process }\end{array}$ \\
\hline
\end{tabular}

The DGI data governance model provides an overarching view of components that are involved in data governance. While insightful, the model focuses mainly on data governance, instead of information governance. In addition, the model is generic, and targets mainly at data governance within a single organization. The Canadian healthcare context is complex in that information resides with healthcare providers who operate as individual businesses, but flows across organizations for the care to be provided. As a result, we believe that it is imperative to develop an information governance model that reflects the complexity of the healthcare context.

\section{Information Governance Model under the Canadian Healthcare Context}

To define the components of an information governance model for the Canadian healthcare context requires a clear definition of purposes to be achieved through governance. Therefore, we propose that under the Canadian healthcare context, the objective of information governance is to achieve better quality care through (1) the governance of healthrelated information for primary care and secondary information use, and (2) the governance of clinical data and research findings/hypotheses for collaboration among clinicians, researchers, and policy makers. In other words, we believe quality healthcare is reliant upon quality health-related information as well as research outputs that inform clinical decisions.

Drawing on the information governance model by the Digital Governance Institute (Digital Governance Institute, 2016), we propose that information governance encompasses four basic components: people (e.g. information governance office, data stakeholders, stewards), processes (e.g. establish accountability, determine decision rights, manage change, stakeholder communication, evaluation and continuous improvement), and policy (e.g. information management, communication, issue resolution, decision rights, and performance management), and technology (e.g. software, hardware, IT infrastructure). Each of the components is elaborated in the following and illustrated in Figure 1.

\section{People component}

The focus of the people component is on identifying key stakeholders involved in the information governance process, understanding their information needs, and creating a governance structure managing information. 
The key stakeholders of a healthcare system encompass the following:

1. Primary clinical data providers and users (e.g. family physicians, hospitals) who provide care to patients. They directly interact with patients, and collect and analyze clinical data.

2. Secondary data users (e.g. governments, community services, researchers) who use the collected clinical data to define/review/revise policies, conduct relevant research, and offer supplementary healthcare services.

3. IT service providers (e.g. e-health Ontario, EMR vendors) who develop and maintain hardware, software, and infrastructures needed for healthcare services.

4. General public (e.g. patients) who receive care provided, and access and manage health information collected through their direct interactions with healthcare providers.

\section{Process component}

In order to achieve high information governance maturity, we have identified the following key processes:

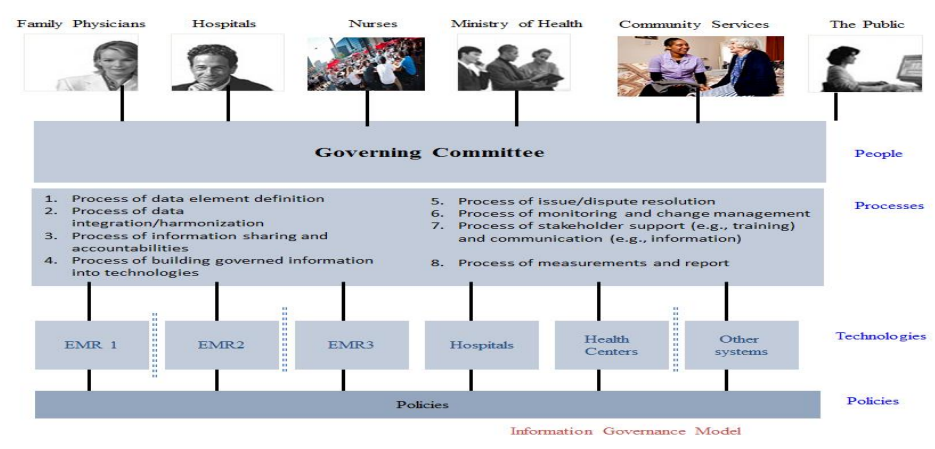

FIGURE 1. Information governance model for Canadian healthcare

\section{Process of data element definition}

Data could include common data used across stakeholders. The data could include common demographic information such as age, gender, ethnic group, and clinical information such as blood pressure, pulse, height, weight, etc. However, different stakeholders would require different data. For example, clinicians are interested only in clinical data, and researchers and policy makers are interested mainly in administrative data. All stakeholders should be involved in defining data elements, data flows, and decision rights.

2. Process of data integration/harmonization

Currently data exist in different formats (e.g. paper, image, structured format), and accessing data is cumbersome. This process helps identify existing poor data integrations as well as data that need to be integrated.

3. Process of information sharing and accountabilities

There are different agreements that need to be defined in order to achieve seamless information sharing across stakeholders. Therefore, there should be a central repository for various sharing agreements and a process flow that guides stakeholders in completing the agreements. This process defines the procedure on information sharing, accountability identification, and agreements management.

4. Process of building governed information into technologies

Once information that needs to be governed is identified and defined, the information needs to be built into technologies to ensure that data collected are structure and stan- 
dard across EMRs. This process ensures that standard data definitions, structures, and formats are followed in technologies.

5. Process of issue/dispute resolution

This process defines the procedure to be followed in case of issues and disputes. 6. Process of monitoring and change management

There should be a regular review process monitoring data collection, use, access, and storage, and offering feedback to help continuous process improvement 7. Process of stakeholder support (e.g. training) and communication (e.g. information)

This process defines trainings that need to be provided to stakeholders for them to better manage information and use technologies, and how the trainings will be provided. For example, when a new service is offered, the general public need to be educated about how to access the service. Similarly, before the introduction of a new information system, healthcare providers need to be trained and supported as to how to use the system effectively.

The process also defines how the stakeholders are kept informed of the information governance-related issues and how the information is to be communicated to stakeholders. For example, senior citizens who do not access information online need to be informed of new services provided via mail, and could be followed up by a phone call to ensure that they understand the nature of the service and ways to access the service. For younger generations, the service information could be pushed through social media. The ultimate goal of the process is to ensure that stakeholders are involved, informed, and engaged in information governance.

8. Process of measurements and report

In order to ensure effective information governance, continuous monitoring of information governance activities is needed. So the process defines and measures outcomes of information governance, and reports back to the stakeholders about the results.

\section{Policy component}

The policy component is necessary to legitimize the importance of information governance and regulates key responsibilities of key stakeholders. The policy component is particularly important in the Canadian context as primary care providers operate individual businesses and are not directly managed by the government.

1. Policy on mandatory data entry and data collection. Quality care requires quality data. One of the key quality criteria is the completeness of data. To obtain a comprehensive view of a patient record, it is imperative that all necessary data are entered to the system. So the governments need to define policies to mandate data entry and associate data entry with compensation.

2. Policy on mandatory incorporation of defined information requirements into IT systems. Advanced information technologies function as a conduit carrying health information to various healthcare stakeholders. It is imperative that defined information requirements are captured in IT systems to ensure a smooth flow of information that is needed for providing quality care.

3. Policy on mandatory information governance committee, composition, and accountability. As health-information is collected, accessed, and used by multiple healthcare providers, an information governance committee needs to be formed to define the processes elaborated above. The policy needs to be in place to ensure that the information governance committee represents the interests and needs of a wide spectrum of stakeholders, and accountability is in place to ascertain desired results from information governance. 


\section{Technology component}

Information technologies have permeated many aspects of our healthcare system and play an increasing role in provision of quality healthcare. As there are a myriad of healthcare technologies available and many new developments emerge every day, the key focus of the technology component is on compatibility and performance of software and hardware deployed and openness, capacity, and scalability of IT infrastructure.

\section{Case study of 18-month baby data from EMRs}

Following the definition of information governance and delineation of information governance components, we apply the concepts to a real case and demonstrate how the concepts could be applied to identify key issues faced in information governance and suggest an action plan to improve the level of information governance.

\section{Case background}

Each year there are approximately 140,000 children born in Ontario who, in the first two years of their life, are seen by family physicians, pediatricians, and nurse practitioners. Approximately $25 \%$ of these children will have some developmental issues when they start school, which should have been recognized and treated much earlier. As a result, the Ontario government provides the enhanced 18-month well-baby visit program, in which the children's information is collected by using two of three tools: the Rourke Baby Record (RBR) or the Denver Developmental Screening Test, and the Nipissing District Developmental Screen (NDDS).

In order to understand the current status of health information collected through the 18-month well-baby visit, the second author interviewed 11 groups of stakeholders (e.g. family physicians, Pediatricians, hospitals) to understand various issues including information collected, methods of information collection, technologies used, technology infrastructure, the type of data or information they would like to obtain, types of decisions they would like to be able to make with the data obtained through a future 18-month data collection system, and issues and problems encountered in collecting and using information needed for diagnosis and analysis. The following reports the findings from the interviews. $\boldsymbol{R B R}$

The Rourke Baby Record is an evidence-based infant/child health record which includes information about baby's growth (e.g. length and weight within one week, two weeks, and one month), physical examination (e.g. skin, ears, eyes and tongue mobility), immunization, and nutrition (e.g.breastfeeding, formula feeding, stool pattern, urine output). Based on the information, primary care providers monitor and assess the physical health of children, and provide education (e.g. safe sleep position) and advice (e.g. parent/bonding).

The RBR is used mostly by Family Physicians. Data collected using the RBR are neither extractable nor transmissible. Currently most data collected using the RBR are through a paper form and kept in paper records. Although there are two of 17 EMR systems which have electronic RBR (eRourke) installed, the data captured is not easily transferrable due to the lack of standard data definitions across the EMR vendors.

In addition, primary care provider representatives complained about poor integration of ill-baby care and well-baby care in EMRs as compared to paper. Paper can be moved around and multiple pages viewed at the same time, but a computer interface only allows a single page to be viewed at one time, limiting user's ability to view ill-baby visits while viewing the well-baby visits in the eRourke.

Poor integration of the immunization module of the EMR and the eRourke form. Data have to be entered in the immunization module for reminders and queries to work properly, but those data do not get sent to the eRourke. If a provider wishes to know the pa- 
tient's immunization status when viewing the eRourke, they have to enter the immunization information again in the eRourke form, creating a burden of double data entry.

\section{Denver development screening tool (DDST)}

The Denver Developmental Screening Tool is used mainly by Pediatricians to assess the developmental progress of children. The test contains up to 125 items divided into four categories including social/personal (i.e. aspects of socialization inside and outside the home), fine motor function (e.g. eye/hand coordination), language (e.g. production of sounds), and gross motor functions (e.g. sitting, walking) (Tidy and Colin, 2014).

Similar to the RBR, data collected through the DDST are neither extractable nor transferrable due to the fact that all data are collected through a paper-based form. The only information available is the number of actual child visits billed from the OHIP fee code by family physicians and pediatricians. However, the visit information is not entirely accurate, as nurse practitioners do not have a fee code to bill, consequently nurse-practitioner provided visits are not reflected through the OHIP fee code.

\section{NDDS}

The NDDS is the most commonly used assessment tool completed by parents in Ontario. It contains a checklist of questions designed to monitor a child's behavioral development. Some questions asked include: "By one month of age, does your child look at you, startle to loud or sudden noise, calm down when comforted?" The factual data about a child's physical development are not captured in the NDDS.

Data captured by the NDDS lie in three formats. The common data format is paperbased captured by the NDDS form which can be downloaded from the NDDS web site. There is an electronic version of the NDDS that provides structured data extractable for data transmission. However, since there is only a single EMR that incorporates the NDDS, resulting in the limited availability of electronic data.

There is also a web-version NDDS (eNDDS) that allows web-filled data to be transferred to EMRs. However, this practice is thwarted due to the complex requirements of authenticating parents, reliably identifying practice providers, and securely transmitting data to EMRs. As a result, most eNDDS completed forms are printed and scanned into the EMR, defeating the purpose of developing the eNDDS in the first place.

As illustrated above, the three tools capture baby information from three different perspectives; however, there is no integration of the collected information. In addition, most information gathered is not transmissible or extractable. Furthermore, not all primary care providers use the same set of tools, preventing consistent monitoring of a baby's development. Moreover, there is no mandatory submission of data when billing the wellbaby incentive code, which means that data may not be sent to a central repository. There is no data sharing agreement infrastructure in place to allow for data to flow, even if the structure for data collection was in place.

Poor integration of the NDDS into the EMR. Currently, most providers have to scan in a paper version of the completed NDDS into the EMR. This means that they have to exit the eRourke to go view the NDDS; both cannot be viewed at the same time. Even in situations where the NDDS is an electronically filled version, providers still have to exit the eRourke to view it, causing fragmentation of information.

\section{Case analysis}

Under the context of a vigorous promotion of EMRs in Canada, the case offers a glimpse of the reality of the EMR adoption, which in the end frustrates primary care providers, confuses policy makers, and affects quality care. What went wrong? 
The stakeholders involved in the 18-month visit include primary care providers such as family doctors, pediatricians, nurses, and hospitals and secondary data users include the government, researchers, and communities who administer and manage the tools. Other stakeholders such as EMR vendors and eHealth Ontario develop and maintain IT systems needed to capture the information collected through the 18-month well-baby visit.

The case reveals the lack of the processes including the process of data element definition, the process of data integration/ harmonization, and the process of building governed information into technologies.

In particular, the lack of the process of data element definition results in the lack of a clear definition of health information collected in the 18-month journey. As illustrated in the case study, there are three tools that capture different information; however, the use of these tools by healthcare providers is inconsistent, resulting in an incomplete picture of a patient's condition.

The fact that the information collected through these tools is stored in various formats including paper, image and electronic which are not easily extractable or transferrable indicates poor data integration and harmonization.

In addition, different EMR vendors are inconsistent in the tools that they support and the structure of the information. This situation exacerbates the issue of data integration and harmonization. Furthermore, it reveals the lack of the process ensuring that the health information needed is incorporated into, and captured consistently in, the EMR technologies.

From the policy perspective, despite the realization of the importance of information governance in quality healthcare, there is no information governance committee to oversee information governance-related issues. Ontario's EMR certification process is still evolving and not geared for certifying specific forms. In addition, there is no plan to include forms as part of the certification process in the near future.

From the technology perspective, there is an evaluation process of performance of EMR systems. The low usability and the lack of integration among EMR systems indicates the lack of control of integration and compatibility across EMRs.

\section{CONCLUSION AND RECOMMENDATIONS}

As illustrated above, we have applied the information governance model to analyze the case and pinpoint the key problems underlying the issues faced in the 18-month well-baby visit. The model helps identify the lack of information governance processes that results in disintegrated information that is difficult to extract and transmit, which affects quality care.

Based on our information governance model, we propose the next step moving forward. First of all, an information governance committee composed of key stakeholders needs to be formed. Second, the committee needs to review the existing practices involved in information governance, and clearly define key information governance processes, policies, and procedures. Third, a chief information governance office and key personnel need to be assigned to implement the identified processes, policies, and procedures. As Canadian healthcare providers are operated as individual businesses, it is imperative that people who are experienced with information governance work closely with the providers to facilitate the implementation. In addition, training and support have to be provided to obtain buy-in. More importantly, policies legitimizing information governance and supporting information governance implementation are essential to ensure the success of information governance. 
Health data are the lifeblood of a healthcare system, and critical to high quality care. Despite the importance of health data, however, a well-defined information governance model for the Canadian healthcare context is lacking. To make up for the gap, we have proposed an information governance model that consists of four components: people, processes, policies, and technologies. Applying the model to the case study on the 18-month well-baby visit, we have highlighted key problems underlying the issues faced in the 18-month journey, and suggested an action moving forward. The study contributes to the academic study on information governance by offering a well-defined model to practitioners by suggesting effective approaches to information governance.

\section{REFERENCES}

Bowen, Rita, and Alisha R. Smith. 2014. Developing an enterprisewide data strategy: Data integrity is a critical concern for both the clinical and financial sides of the healthcare enterprise, ensuring both quality of care provided and accurate payment for services--and that also makes it a critical concern for the CFO. Healthcare Financial Management 68, no. 4, pp. 86-90.

Canada Health Infoway. 2007. White paper on information governance of the interoperable electronic health record (EHR). URL: goo.gl/S2zwka (accessed August 4, 2016).

Digital Governance Institute. 2016. The dgi framework. URL: goo.gl/oE4xjr (accessed October 10, 2016).

eHealth Ontario. 2016. It's working for you. URL: goo.gl/itExhn (accessed October 10, 2016).

Gerrard, Michae. 2010. IT governance. URL: goo.gl/7IsNQh (accessed September 8, 2015).

Greene, Jan. 2014. Better data through IT governance. Hospitals \& Health Networks. URL: goo.gl/0OYKyX (accessed August 11, 2016).

Hripscak, George, and David J. Albers. 2012. Next generation phenotyping of electronic health records. Journal of the American Medical Informatics Association 20, no. 1: 117-121.

Isaacs, Leigh. 2016. Information governance strategy isn't a project. Computer Weekly, 11-15.

Ontario Medical Association. 2014. Insights 4 care program: Strategic context and program overview. URL: goo.gl/uaSvDu (accessed August 11, 2016).

Reeves, Mary G., and Rita Bowen. 2013. Developing a data governance model in healthcare. Health Care Financial Management. URL: goo.gl/GyJYQH (accessed August 12, 2016).

Scardilli, Brandi. 2014. Celebrating information governance. Information Today 31, no. 4: 33-36.

Smallwood, Robert. 2014. Defining the differences between information governance, IT governance, \& data governance. URL: goo.gl/OxZaXX (accessed October 8, 2015).

Vuchnich, Allison. 2015. Number of doctors on the rise in canada and payments hit \$24 billion: Report. URL: goo.gl/oSbxCb (accessed October 10, 2015).

Wood, Colin. 2014. Data governance: The public sector's next big frontier. Government Technology. URL: goo.gl/Wmkgmf (accessed September 8, 2015).

Weill, Peter, and Jeanne W. Ross. 2005. Designing IT governance. MIT Sloan Management Review 46, no. 2: 26-34. 